Sujit K. Pandit MD, Sarla P. Kothary MD, Uma A. Pandit MD, Mary K. Mathai MD

\title{
Comparison of fentanyl and butorphanol for outpatient anaesthesia
}

Equianalgesic doses of burorphanol $\left(40 \mu \mathrm{g} \cdot \mathrm{kg}^{-1}\right)$ and fenranyl $\left(2.0 \mu \mathrm{g} \cdot \mathrm{kg}^{-1}\right)$ were compared as supplements to balanced general anaesthesia for outpatient laparoscopic procedures. Thirtysix adult female patients (ASA physical status I or II) participated in the study. The study drugs (butorphanol or fentanyl) were given just prior to induction of anaesthesia in a double. blind fashion. Following induction with a standard dose of thiopentone and tracheal intubation using succinylcholine, nitrous pxide in oxygen and a succinylcholine infusion were ased for maintenance of anaesthesia. Seventeen of the 18 patients in the butorphanol group and 14 of the 18 patients in the fentanyl group showed signs of light anaesshesia and required supple. mentation with isofturane. Induction, mainenance and recov. en characteristics were not different in the two groups except that the post-intubation arterial pressure and heart rate in the fentanyl group were significantly higher than the base line values and the patients receiving butorphanol were more drowsy and also more pain-free in the postoperative period. The incidence of nausea and vomiting was high in both groups. Overall, butorphanol $\left(40 \mu \mathrm{g} \cdot \mathrm{kg}^{-1}\right)$ used as part of a standard balanced general anaesthetic for a standard outpatient procedure was not superior to fentanyl ( $\left.2 \mu \mathrm{g} \cdot \mathrm{kg}^{-1}\right)$ used in the same fashion.

\section{Key words}

ANAESTHESIA: outpatient; ANALGESICS: butorphanol, fentanyl.

From the Department of Anesthesiology, University of Michigan Hospital, Ann Arbor, Michigan.

Address correspondence to: Dr. Sujit K. Pandit, Room IG323/Box 0048, University of Michigan Hospitals, Ann Arbor, Michigan 48109 .

Presented at the 3rd Annual Conference of the Sociely of Ambulatory Anesthesia, Williamsburg, April 1985.

The project was partially supported by a grant from Bristol Laboratories.
The choice of anaesthetic agents and adjuvants during ambulatory surgery is of critical importance. Common side effects of general anaesthesia include prolonged drowsiness, dizziness, amnesia, nausea, womiting, headache, muscle pain and general malaise. However, most of these side effects are unacceptable for patients who are planning to go home two to three hours after the operation. 1,2

It is a common practice among anaesthetists to include a small dose of narcotic analgesic as part of the balanced anaesthetic technique for short outpatient procedures. This not only minimizes the requirement for potent anaesthetic agents during induction and maintenance of anaesthesia, but also provides a more comfortable recovery from anaesthesia without unduly prolonging it. ${ }^{3}$ Shortacting narcotic agonists, such as fentanyl or sufentanil are often used for this purpose. However, both of these narcotje receptor agonists can cause respiratory depression, dizziness, nausea and vomiting. ${ }^{2}$ We qucstioned whether butorphanol, an agonist-antagonist type of analgesic, a non-scheduled drug (because of low addiction liability) and which has a low propensity to cause respiratory depression, nausea, and vomiting ${ }^{4,5}$ would be a better choice. The purpose of the present study was to compare equipotent moderate doses of fentanyl and butorphanol, used as a part of a balanced anaesthetic technique in a patient population of healthy adult females undergoing outpatient laparoscopic procedures.

\section{Methods}

Prior institutional approval for the study was obtained, and each patient signed an informed consent document. In the present study, fentanyl $50 \mu \mathrm{g}(1 \mathrm{ml})$ was considered equipotent to butorphanol $1 \mathrm{mg}(1 \mathrm{ml}){ }^{6}$ The doses utilized for the comparison were either fentanyl $2 \mu \mathrm{g} \cdot \mathrm{kg}^{-1}$ or butorphanol $40 \mu \mathrm{g} \cdot \mathrm{kg}^{-1}$. For a $75 \mathrm{~kg}$ patient the dose would be either fentanyl $150 \mu \mathrm{g}$ or butorphanol $3.0 \mathrm{mg}$. Both agents were given intravenously, in a randomly distributed double-blind fashion, according to the protocol described below (no placebo was used). The medications were supplied in identical vials with only serial numbers on them. Each $\mathrm{ml}$ contained either fentanyl $50 \mu \mathrm{g}$ or butorphanol $1.0 \mathrm{mg}$. Dispensing was done on the basis of $0.04 \mathrm{ml} \cdot \mathrm{kg}^{-1}$. 
Thirty-six adult female patients scheduled for outpatient laparoscopic procedures (cither diagnostic laparoscopy or laparoscopic tubal ligation) were randomly assigned to one of two study groups. All patients were of ASA physical status I or II. Their ages ranged between 18 and 45 years and weights between 50 and $100 \mathrm{~kg}$. No premedication was given. Eah patient received a standard anaesthetic including preoxygenation, precurarization (d-tubocurarine $3 \mathrm{mg}$ IV), followed either by fentanyl or butorphanol in a double-blind fashion in the doses described above, and, two minutes later, thiopentone $4 \mathrm{mg} \cdot \mathrm{kg}^{-1}$ immediately followed by succinylcholine $1.5 \mathrm{mg} \cdot \mathrm{kg}^{-1}$. Oral tracheal intubation was performed when the patients were fully paralyzed. Anaesthesia was maintained with nitrous oxide and oxygen (4.2 L. $\min ^{-1}$ ) and a continuous succinylcholine infusion (approximately $100 \mu \mathrm{g} \cdot \mathrm{kg}^{-1} \cdot \mathrm{min}^{-1}$ ). Whenever any sign of light anaesthesia such as tachycardia, hypertension, swcating, lacrimation or muscle movement occurred, isoflurane was added in appropriate doses.

Ventilation was mechanically controlled throughout the operation. No routine anticholinergic agent or prophylactic antiemetic was used. Before, during, and after anaesthesia, monitoring of arterial blood pressure by an automatic device, (Dinamap), ECG and respiratory rates was carried out.

The frequency of side effects, e.g., nausea, vomiting, drowsiness, pain, headache, etc., were noted following direct questioning of the patient. Drowsiness was assessed ${ }^{7}$ on a scale of 1 to 5 where 1 is equal to no drowsiness and 5 is equal to unresponsive. Grades 4 or 5 were considered excessive drowsiness. Pain in the Recovery Room was graded subjectively as none, mild, moderate or severe. Moderate to severe pain for more than $15 \mathrm{~min}$ utes was considered excessive pain. Recovery times (to orientation, to ambulation, and to discharge) were recorded following standard clinical criteria (see below) and measured from cessation of the inhalation anaesthetic (nitrous oxide). The standard discharge criteria (Wetchler criteria $^{8}$ were used: fully awake and alert, no rcspiratory distress, gag and cough reflex present, stable vital signs (blood pressure, pulse rate, respiratory rate), minimum or no nausea, no bleeding, ambulatory, voided and tolerated oral fluid. Vital signs were recorded every $15 \mathrm{~min}$ utes, and analgesic (Fentanyl) and antiemetic (prochlorperazine) requirements in the recovery room were noted. All patients were interviewed 24 hours after the operation by telephone to gather further information regarding residual side effects and analgesic (Tylenol) requirements. One of the investigators ("blind" to the group assignment), did all the evaluations in the Recovery Room and conducted the postoperative interviews.

Repeated measures (two-way analysis of variance)
TABLE I Demographic information (mean \pm SD)

\begin{tabular}{lcc}
\hline & $\begin{array}{l}\text { Butorphanol } \\
n=18\end{array}$ & $\begin{array}{l}\text { Fentanyl } \\
n=18\end{array}$ \\
\hline Age (yr) & $29.56 \pm 6.37$ & $34.22 \pm 5.94$ \\
Height (inch) & $63.61 \pm 2.62$ & $63.67 \pm 2.85$ \\
Weight (lb) & $138.39 \pm 31.57$ & $138.11 \pm 25.49$ \\
Duration of surgery (min) & $34.17 \pm 10.74$ & $32.83 \pm 11.14$ \\
Duration of anaesthesia (min) & $63.61 \pm 13.26$ & $60.28 \pm 11.94$ \\
\hline
\end{tabular}

$\mathrm{p}=\mathrm{NS}$ (unpaired $\mathrm{i}$ test).

and Student's t test for parametric data and the Chisquare test for nonparametric data were used for statistical analysis. A p value $<0.05$ was considered significant.

\section{Results}

Demographic parameters of age, height, weight, and duration of operation and anaesthesia were comparable in the two groups (Table I). Seventeen out of 18 patients in the butorphanol group and 14 out of 18 patients in the fentanyl group required supplementation with isoflurane because signs of light anaesthesia were present. There was no statistical difference between the fentanyl and butorphanol groups regarding the need for supplemental isoflurane.

The changes in pulse rate and systolic blood pressure during the peri-induction period are shown in Table II. The only significant change occurred two minutes after tracheal intubation in the fentanyl group when both the heart rate arid systolic blood pressure were significantly higher than the preoperative baseline values. The haemodynamic changes in the butorphanol group (preoperative baseline vs postintubation) were not statistically signifcant. There were no significant changes in blood pressure and pulse rates during maintenance of anaesthesia or in the Recovery Room (not shown).

Recovery times measured from the time nitrous oxide was stopped, appear in Table III. Three different recovery times were noted: time to orientation (name, place, birthdate), time to ambulation, and time to discharge. The differences in the recovery times between the two groups were not statistically significant.

Postoperative side effects were elicited by direct questioning of the patient. Responses are shown in Table IV. Nausea and vomiting were the most common side effects; 10 of 18 (55 per cent) patients in the butorphanol group and 11 of 18 ( 61 per cent) in the fentanyl group had nausea while in the Recovery Room. Of these, eight patients in the butorphanol group and nine in the fentanyl group also either vomited or retched. Seven ( 40 per cent) in each group experienced dizziness.

Significant drowsiness was present in eight patients in the butorphanol group and in three patients in the fentanyl 
TABLE II Result: blood pressure, pulse rate

\begin{tabular}{|c|c|c|c|c|}
\hline & \multicolumn{2}{|c|}{$\begin{array}{l}\text { Systolic blond pressure } \\
\text { (mean } \pm S D)\end{array}$} & \multicolumn{2}{|c|}{$\begin{array}{l}\text { Pulse rate (heatsimin) } \\
\text { (mean } \pm S D)\end{array}$} \\
\hline & Butorphanol & Fentamyl & Buturphanol & Fenlaryl \\
\hline Holding room & $116.0 \pm 9.4$ & $118.5 \pm 13.9$ & $80.0 \pm 16.9$ & $73.3 \pm 9.1$ \\
\hline Preinduction & $125.9 \pm 17.7$ & $121.8 \pm 11.4$ & $85.0 \pm 19.8$ & $80.3 \pm 15.8$ \\
\hline Before intubation & $117.3 \pm 10.7$ & $116.1 \pm 13.3$ & $83.8 \pm 18.9$ & $80.3 \pm 17.6$ \\
\hline 2 min after intubation & $132.1 \pm 20.5$ & $153.6 \pm 29.0^{*}$ & $94.9 \pm 14.8$ & $107.8 \pm 18.0^{*}$ \\
\hline
\end{tabular}

Repeated measures (two way analysis of variance) and Student's t test $\mathrm{*} p=0.001$ compared to holding room.

TABLE III Recovery time (minutes) (mean \pm SD)

\begin{tabular}{lcc}
\hline & Butorphanol & Fenranyl \\
\hline Time to orientation $(\times 3)$ & $20.3 \pm 13.6$ & $13.4 \pm 9.3$ \\
Time to ambulate & $192.9 \pm 68.1$ & $148.9 \pm 45.3$ \\
Time to discharge (hame) & $230.7 \pm 76.5$ & $197.5 \pm 69.1$ \\
\hline
\end{tabular}

All times counted from discontinuation of $\mathrm{N}_{2} \mathrm{O}$.

$p=$ NS (unpaired t test).

group one hour after admission to the Recovery Room $(p<0.05)$. One patient in the fentanyl group complained of awareness (hearing of conversation and feeling of pain) during the operation and one patient in the butorphanol group complained of unpleasant dreams during the operation. Significant postoperative pain ssevere to moderate) in the Recovery Room was experienced by six patients receiving butorphanol and 17 patients receiving fentanyl (Table IV) $(p<0.05)$. Severe nausea and vomiting lasted for 24 hours in one patient in each group; neither required hospitalization. Table $V$ show's the frequency of postoperative analgesic and antiemetic ther apy. The differences between the groups were not statistically significant.

\section{Discussion}

Neither fentanyl $\left(2 \mu \mathrm{g} \cdot \mathrm{kg}^{-1}\right)$ nor butorphanol $\left(40 \mu \mathrm{g} \cdot \mathrm{kg}^{-1}\right)$ along with nitrous oxide provided a clinically acceptable depth of anaesthesia for the laparoscopic procedures. Almost all anaesthetics needed supplementation with isoflurane. In spite of this, one patient in each group had either dreaming or awareness during the surgical procedure. It is not clear if this occurred before or after isoflurane supplementation. Whether larger doses of fentanyl or butorphanol would have prevented these problems is not known. Although only one dose of butorphanol has been compared with an equivalent dose of fentany], we deliberately used the maximum dose of cach agent which most anaesthetists would feel comfort-
TABLE IV Postoperative side effects

\begin{tabular}{llr}
\hline & $\begin{array}{l}\text { Butorphanol } \\
(n=18)\end{array}$ & $\begin{array}{l}\text { Fentanyl } \\
(n=18)\end{array}$ \\
\hline Nausea only & $10(55.5 \%)$ & $11(61.1 \%)$ \\
Nausea and vomiting & $9(50 \%)$ & $8(44.4 \%)$ \\
Dizziness & $7(38.9 \%)$ & $7(38.9 \%)$ \\
Drowsiness & $8^{*}(44.4 \%)$ & $3(16.6 \%)$ \\
Dreaming & $1(5.5 \%)$ & $1(5.5 \%)$ \\
Excessive pain & $6(33.3 \%)$ & $17^{*}(94.4 \%)$ \\
Scvere nausea and vomiting & $1(5.5 \%)$ & $1(5.5 \%)$ \\
$\quad$ for 24 hours & & \\
\hline
\end{tabular}

*p $<0.05$ (Chi square test).

able in using for a short outpatient procedure. While larger doses might have improved the quality of anaesthesia, this might not be acceptable for clinical use in patients who are expected to go home 2-3 hours after the operation. Addition of a low concentration of a volatile agent such as isoflurane from the beginning should make the course of anaesthesia smoother, without the problems of long recovery time.

Apart from the fact that butorphanol gave better protection against autonomic stimulation to tracheal intubation, there was no other significant difference between butorphanol and fentanyl during either induction or maintenance of anaesthesia.

TABLE V Postoperative therapy (24 hours)

\begin{tabular}{llr}
\hline & $\begin{array}{l}\text { Butorphonal } \\
(n=18)\end{array}$ & $\begin{array}{r}\text { Fentanyl } \\
(n=18)\end{array}$ \\
\hline Analgesics & & \\
$\quad$ Recovery room (fentanyl IV) & $3(16.6 \%)$ & $8^{*}(44.4 \%)$ \\
Home ("Tyleno]" Po) & $2(11.1 \%)$ & $11^{*}(61.1 \%)$ \\
Antiemelic (total) & $7(38.9 \%)$ & $7(38.9 \%)$ \\
(Prochlorperazine) & & \\
\hline
\end{tabular}

${ }^{*} \mathrm{p}<0.05$ (Chi square test). 
The postoperative periods in the Recovery Room and at home were also remarkably similar in both groups except a higher reported incidence of pain in the fentanyl group and more drowsiness in the butorphanol group. Rapid redistribution of fentanyl likely explains this difference. ${ }^{9}$

The incidence of nausea and vomiting was high in both groups. Fifty-five per cent of the patients in the butorphanol group and 61 per cent in the fentanyl group experienced nausea. Approximately 40 per cent of the patients in each group required antiemetic therapy.

It is generally believed that female patients undergoing laparoscopic procedures are more likely to experience nausea/vomiting postoperatively ${ }^{1,10}$ and use of narcotics as part of the anaesthetic management is known to cause more nausea and vomiting. ${ }^{1-13}$ Prophylactic antiemetic therapy (e.g., small dose of droperidol) has been recommended. ${ }^{14-16}$ We did not use a prophylactic antiemetic agent.

Thus, the present study was unable to show any advantage for butorphanol over fentanyl as part of a balanced anaesthetic technique for outpatient laparoscopic procedurcs. Since butorphanal is a nonscheduled drug (because of its low liability for addiction) there may be some administrative advantage in using it.

In summary, neither fentanyl nor butorphanol in the doses used appears to be the ideal narcotic component of a balanced anaesthetic technique for outpatient laparoscopic procedures. A volatile anaesthetic (isoflurane) was necessary in almost all cases; moreover, patients in both groups experienced side effects during the recovery pcriod in the forms of nausea, vomiting, dizziness or drowsiness. Significantly more patients in the butorphanol group had drowsiness and more patients in the fentanyl group experenced excessive pain. Use of a low concentration of a volatile anaesthetic agent from the outset and addition of a small dose of prophylactic antiemetic agent might have improved the quality of anaesthesia and minimized postoperative side effects. Further research is necessary in the fields of anaesthesia for outpatient surgery in an attempt to minimize the common postoperative side effects.

\section{References}

1 Dhamee MS, Gandhi SK, Callen KM et al. Morbidity after outpatient anesthesia - a comparison of different endotracheal anesthetic techniques for laparoscopy. Anesthesiology 1982; 57: A375.

2 Nutaf $H E$. Complications associated with ambulatory surgery. JAMA 1980; 244: 1116.

3 Horrington RW, Moyers JR, Johnson BH er at. Etomidate vs thiopental with or without fentanyl - a comparative study of awakening in man. Anesthesiology 1980; 52 : $362-4$.
4 Nagashima H, Karamanian A, Malovany R et al. Respiratory and circulatory effects of intravenous butorphanol and morphine. Clin Pharmacol Ther 1976; 19: 738-45.

5 Kallos $T$, Caruso ES. Respiratory effects of butorphanol and pethidine. Anaesthesia 1979; 34: 633-7.

6 Jaffe $J H$, Martin WR. Opioid analgesics and antagonists. The Pharmacological Basis of Therapeutics, 7th Ed. New York, MacMillan, 1985

7 Pandit SK, Heisterkamp DV, Cohen PJ. Further studies of the antirecall effect of lorazepam. A dose-time-effect relationship. Anesthesiology 1976; 45: 495-500.

8 Wetchler BV. Problem solving in the postanesthesia care unit. Anesthesia For Ambulatory Surgery. Edited by BV Wetchler, Philadelphia, JB Lippincott Co., 1985.

9 MCClain DA, $H_{1 / g} \mathrm{C}$. Intravenous fentanyl kinetics. Clin Pharmacol Ther 1980; 28: 106-14

10 Dawson B, Reed WA. Anaesthesia for day-care surgery: a symposium. III. Anaesthesia for adult surgical outpatients. Can Anaesth Suc J 1980; 24: 409.

11 Dundee JW. Clark RJJ, Loan WB. A comparison of the sedative and toxic effects of morphine and pethidine. Lancet 1965; 1: 1262-3.

12 Dindee JW. Kinwan MJ, Clarke RSJ. Anesthesia and premedication as factors in postoperative vorniting. Acta Anaesthesiol Scand 1965; 9: 223-31.

13 Clarke RSJ. Nausea and vomiting. Br 3 Anaesth 1984; 56: $19-27$.

14 Kortilla K, Kauste A, Auvinen J. Comparison of domperidone, droperidol and metoclopramide in the prevention and treatment of nausea and vomiting after balanced general anesthesia. Anesth Analg 1979; 58: 396-400.

15 Wetchler BV, Collins IS, Jacob LC. Antiemetic effects of droperidol on the ambulatory surgery patient. Anesthesiology Review 1982; 9: 23-6.

16 Abramowitz MD, Oh TH, Epstein SB et al. The antienetic efficacy of droperidol following outpatient strabismus surgery in children. Anesthessiology 1983; 59: 579-83. 
Résumé

Des doses équianalgésiques de butorphanol $\left(40 \mu \mathrm{g} \cdot \mathrm{kg}^{-1}\right)$ et fentanyl ( $\left.2.0 \mu \mathrm{g} \cdot \mathrm{kg}^{-1}\right)$ ont été comparées lorsqu' utilisées comme supplément dans une anesthésie générale balancée pour des patientes externes devant subir des procédures chirurgicales sous laparoscopie. Trente-six patientes (ASA classe l et II) ont participé à cette étude. Ces médicaments (butorphanol ou fentanyl) ont été administrés à double insu juste avant l'induction de l'anesthésie. Après l'induction avec des doses standard de thiopentone l'intubation fut accomplie avec la succinylcholine et le maintien avec du protoxyde d'azote/ $\mathrm{O}_{2}$ et perfusion de succinylcholine. $17 / 18$ patientes du groupe butorphanol et 14118 patientes du groupe fentanyl ont démontré des signes d'anesthésie légère requérant l'addition d'isoflurane. L'induction, le maintien et le réveil n'étaient pas différents dans les deux groupes d l'exception de l'augmentation significarive comparativement aux données de départ de la tension artérielle et de la fréquence lors de l'intubation dans le groupe fentanyl. Les patientes ayant reçu du butorphanol édaient plus somnolentes et libres de douleur en période post-opératoire. L'incidence de nausées, vomissements était élevée dans les deux groupes. En général le butorphanol $\left(40 \mu \mathrm{g} \cdot \mathrm{kg}^{-1}\right)$ utilisé lors d'une anes. thésie générale balancée pour des pracédures sur des patientes externes n'étaient pas supérieur au fentanyl $\left(2 \mu \mathrm{g} \cdot \mathrm{kg}^{-1}\right)$ utilisé de la même façon. 